\title{
Perception of Environment and Educational Outcomes by Students and Faculty in Traditional Versus Integrated Curriculum
}

\author{
Azra Jamil
}

\begin{abstract}
Objective: To find out the differences in the perceptions of the environment and educational outcomes of the students and the faculty from the traditional and integrated curriculum using DREEM inventory.

Study Design: Cross-sectional study.

Place and Duration of Study: Sindh Medical College and Liaquat National Medical College, Karachi, from December 2016 to December 2017.

Methodology: Two medical colleges in Karachi, a traditional (Liaquat National Medical College) and an integrated (Sindh Medical College) curricular environments, were selected. Using DREEM questionnaire (for the students and adapted for faculty responses), data was collected from 157 preclinical and clinical faculty and students. Mean and standard deviation were calculated for each of the 50 items separately, for the domains, and for the global DREEM score. A comparative analysis was performed using student's t-test between the traditional and integrated environments students, faculty, and the students with the respective medical college.

Results: Overall response rate was $92.6 \%$ (101 students, 56 faculty members). The study found difference in the perception of students and faculty in the integrated curricular environment. The traditional curricular environment had no difference in perceptions between faculty and students. Generally, students from the integrated curricular environment had similar perceptions as the traditional curricular environment students.

Conclusion: Overall the integrated curriculum-environment faculty and students both had more positive than negative perceptions of environment. There is a difference in the perceptions of students and faculty working in the integrated curricular environment. All the negative scored areas need to be addressed.
\end{abstract}

Key Words: Traditional curriculum, Integrated curriculum, Faculty, Environment, Curriculum, Students, Medical.

\section{INTRODUCTION}

Educational environment is the backbone of medical curriculum. ${ }^{1}$ Learning environment has been identified for the evaluation of medical education programme. ${ }^{2}$ Learning environment has considerable effects on learning, academic progress as well as on the physical and the mental wellbeing of students. 1,3 Evidence suggests that a favourable learning environment results in positive learning outcome.4,5 Maintaining quality and validity in the educational curricula, the evaluation of the educational environment at both academic and clinical sites is important for maintaining and improving the quality of educational curriculum. 6,7

It has been advocated that a positive learning environment enhances students' motivation, promotes knowledge and skills. Therefore, the evaluation of learning environment is regarded as the key to deliver high quality education. All around the world, studies have been conducted to assess the effect of the

Department of Gynaecology, Al-Kidmat Hospital, Nazimabad, Karachi, Pakistan

Correspondence: Dr. Azra Jamil, House No. 177 A-1, Block 13D/2, Gulshan-e-Rabia, Karachi, Pakistan

E-mail:drazra@live.com

Received: April 06, 2018; Accepted: August 30, 2018 educational environment on students' outcome, happiness, and motivation. $3,6-9$

In order to achieve the best learning outcome in medical institutions, the medical educators throughout the world are trying to make the curriculum student-friendly, since an optimal evaluation process requires 360 degrees perspectives. 10 In this context, the students' feedback about the teaching faculty and administration holds great significance.

Following the Pakistan Medical and Dental Council (PMDC) initiative towards integrated curriculum in all medical colleges, the system-based interdisciplinary medical curriculum is getting rapid popularity in Pakistan and many medical institutions are in transition from traditional subject-based curriculum to the integrated curriculum. The role of teaching faculty during the transition period from traditional to integrated curriculum is of utmost importance and plays a vital role in the changing trends.6,10,11 Further, it is also imperative to see the comparative evaluation of different curricular environments so as to understand the strengths and weaknesses of two different environments for corrective measurements. ${ }^{12-13}$

Despite the evidence in favour of integrated curriculum, a comparison of integrated and traditional curriculum has never been studied in Pakistan. The perceptions of important stakeholders, such as the students and 
faculty, were never recorded for the two milieus of curriculums. ${ }^{13,14}$ The current research provides an opportunity to assess and evaluate the perception of students and teachers about two different curricular environments. This comparative analysis may also serve as a benchmark to predict the students' performance in relation to the curricular environment.

The objective of this study was to find out the differences in the perceptions and educational outcomes of the students and the faculty practising the traditional and integrated curriculum using DREEM inventory.

\section{METHODOLOGY}

The study was conducted in two Medical Colleges of Karachi, from December 2016 to December 2017, one was the representative of traditional curricular environment (TCE) and the other had established integrated curricular environment (ICE). DREEM questionnaire was used to assess the educational curricular environment. It has been used to assess in a variety of educational environment and has been adapted for various respondents such as the faculty and students. Fifty items of the DREEM tool cover five distinct domains aimed to encompass the different aspects of learner/educator perception. The research study was conducted after approval from the institutional review board of the respective medical colleges.

Both preclinical and clinical students and faculty members were contacted. The study proforma were distributed in each of the medical colleges through the respective institutional representatives and was supervised by the principal investigator. The study participants, both students and faculty, were selected through convenient sampling. An informed consent was taken from all the respondents. Anonymity and confidentiality was reassured. All the data was field edited and then entered into the EpiData 3.0 data entry programme. SPSS version 21 was used in analysing the data. Out of the total 110 proforma distributed to students, 103 were returned and of them two proforma were excluded from the analysis due to substantial missing data. The final analysis was based on the 101 students' proforma. Four proforma were returned blank and excluded from the analysis. Mean and standard deviation was calculated for each of the 50 items separately, for the domains, and for the global DREEM score. A comparative analysis was done to see the mean difference in DREEM score between the traditional and integrated environment students and faculty, separately. Independent sample t-test was used separately for each of the four comparisons with means and standard deviations. Results are reported at the $p$-value $\leq 0.05$.

\section{RESULTS}

A total of 170 respondents ( 110 from the students and 60 from the faculty) were aimed in the beginning. The response rate for students was 103/110 (93.6\%), while the faculty response rate was $56 / 60(93.3 \%)$. The results of this study are based on the $101(91.8 \%))$ received from students and $56(93.3 \%)$ responses from the faculty of both institutions. The minimum and maximum scores by the students were 1.4 and 3.0, respectively; while faculty scores 1.0 and 3.3 were minimum and maximum, respectively.

Table I shows the comparative analysis between the students of the traditional and integrated learning environments. This study reports a statistically significant difference in academic domain only $(p=0.035)$. On an average, the students from traditional curricular environment scored 2 points higher than the integrated curricular environment students. All other domains including the global score of the DREEM among students were showing no difference.

There was a statistically significant difference in the academic domain only. The overall mean difference between the faculties showed statistically significant difference $(p=0.01)$. Table I depicts the domain-wise and total scores based on the DREEM questionnaire. Both the faculties scored low on the items $8,9,39$, and 50 . Traditional environment faculty admitted to ridicule students (0.7) more than compared to the integrated environment faculty (1.4, Table I).

Table I: Comparison of DREEM scores within faculty and students in the traditional and integrated curricular environments.

\begin{tabular}{|c|c|c|c|c|}
\hline DREEM faculty scores & TCE $(n=25)$ Mean \pm SD & ICE $(n=31)$ Mean $\pm S D$ & t-stats & P-value \\
\hline Perception of learning & $30.9 \pm 2.8$ & $32.4 \pm 4.5$ & 1.5 & 0.13 \\
\hline Perception of teacher & $26.6 \pm 4.2$ & $29.4 \pm 3.9$ & 2.6 & 0.01 \\
\hline Academic self-perception & $19.5 \pm 3.6$ & $22.4 \pm 2.9$ & 3.3 & 0.002 \\
\hline Perception of atmosphere & $29.5 \pm 3.3$ & $31.7 \pm 4.6$ & 1.9 & 0.06 \\
\hline Social self-perception & $17.3 \pm 3.9$ & $18.3 \pm 2.5$ & 1.3 & 0.20 \\
\hline Global FACULTY scores & $126.7 \pm 13.4$ & $137.2 \pm 16.2$ & 2.7 & 0.01 \\
\hline DREEM STUDENTS scores & TCE $(n=54)$ Mean $\pm S D$ & ICE $(n=47)$ Mean \pm SD & t-stats & P-value \\
\hline Perception of learning & $27.9 \pm 7.7$ & $27.1 \pm 7.2$ & -0.5 & 0.6 \\
\hline Perception of teacher & $25.1 \pm 5.6$ & $26.3 \pm 4.9$ & 1.2 & 0.3 \\
\hline Academic self-perception & $20.8 \pm 5.6$ & $18.2 \pm 6.7$ & -2.1 & 0.035 \\
\hline Perception of atmosphere & $30.6 \pm 6.2$ & $28.1 \pm 7.2$ & -1.8 & 0.07 \\
\hline Social self-perception & $17 \pm 3.7$ & $15.9 \pm 4.5$ & -1.4 & 0.16 \\
\hline Global STUDENTS scores & $121.4 \pm 24.9$ & $115.6 \pm 27.1$ & 1.1 & 0.30 \\
\hline
\end{tabular}

TCE = Traditional curricular environment; ICE = Integrated curricular environment 
Table II: Comparison of DREEM scores between faculty and students within the traditional and integrated curricular environments.

\begin{tabular}{|c|c|c|c|c|}
\hline \multirow[t]{2}{*}{ Traditional curricular environment } & Faculty $(\mathrm{N}=31)$ & Students $(N=54)$ & t-stats & $\mathrm{p}$-value \\
\hline & Mean \pm SD & \multicolumn{3}{|l|}{ Mean $\pm S D$} \\
\hline Perception of learning & $30.9 \pm 2.8$ & $27.9 \pm 7.7$ & 2.1 & 0.041 \\
\hline Perception of teacher & $26.6 \pm 4.2$ & $25.1 \pm 5.6$ & 1.3 & 0.20 \\
\hline Academic self-perception & $19.5 \pm 3.6$ & $20.8 \pm 5.6$ & -1.1 & 0.30 \\
\hline Perception of atmosphere & $29.5 \pm 3.9$ & $30.6 \pm 6.2$ & -0.8 & 0.40 \\
\hline Social self-perception & $17.3 \pm 3.3$ & $17 \pm 3.7$ & 0.4 & 0.72 \\
\hline Total & $126.7 \pm 13.4$ & $121.4 \pm 24.9$ & 1.1 & 0.30 \\
\hline \multirow[t]{2}{*}{ Integrated curricular environment } & Faculty $(\mathrm{N}=25)$ & Students $(N=47)$ & t-stats & $\mathrm{p}$-value \\
\hline & Mean & \multicolumn{3}{|l|}{ Mean } \\
\hline Perception of learning & $32.4 \pm 4.5$ & $27.1 \pm 7.2$ & 3.3 & 0.001 \\
\hline Perception of teacher & $29.4 \pm 3.9$ & $26.3 \pm 4.9$ & 2.7 & 0.009 \\
\hline Academic self-perception & $22.4 \pm 2.9$ & $18.2 \pm 6.7$ & 3 & 0.003 \\
\hline Perception of atmosphere & $31.7 \pm 4.6$ & $28.1 \pm 7.2$ & 2.2 & 0.03 \\
\hline Social self-perception & $18.3 \pm 2.5$ & $15.9 \pm 4.5$ & 2.5 & 0.013 \\
\hline Total & $137.2 \pm 16.2$ & $115.6 \pm 27.1$ & 3.7 & $<0.001$ \\
\hline
\end{tabular}

Overall, the results indicate that students perception of learning significantly differ from the faculty perception of learning. The global scores between the students and the teachers also had statistically significant difference. All other domains did not show any statistical difference. An in-depth analysis to compare the mean scores between the respective curricular environment students versus faculty revealed interesting findings. Table II shows the comparison of students and faculty in their respective curricular environments. None of the five domains, including the global DREEM score, achieved statistical significance in the traditional environment for students versus faculty comparison. There was a marked difference between the integrated students and the faculty in all the domains and global DREEM scores. On an average, faculty perceptions were more positive compared to students.

\section{DISCUSSION}

DREEM has been used by a variety of institutions to assess the environment as perceived by the students, and to diagnose the positive and negative aspects of the institutions. It has also been used to compare the curricula in transition.4,5,11,13,15-19

Very few studies have looked into the perspective of stakeholders other than the students such as the teaching faculty. In contrast to this study findings, Shahnaz and colleague reported similar perception of faculty and students on DREEM in an integrated curriculum. ${ }^{15}$ This could be due to various reasons because the DREEM data was used on an item scale of $0-4$, with a sample size twice as large as the stated study and the socioeconomic differences in the study population.

The perception of the educational environment by the medical teachers is significant not only for themselves but also for the students, while the environment of any medical college is determined by the behaviour of both the students and the teachers. 1 The faculty viewpoint about the students' perception and experience has not been explored in-depth; hence, this comparison was performed. 15

Generally, the students scored more positive than negative on DREEM; however, TCE global scores were better than ICE. On an average, both the TCE and ICE students scored lower than their respective faculty respondents. This demonstrates the gap in the perceptions between students and faculty. The gap was more pronounced in the TCE than ICE. Except the perception of learning and academic self-perception domains, both the TCE and ICE had similar perceptions of their academic environment. The results are in line with the earlier findings for these domains. However, interestingly the TCE students scored more than the ICE at each domain level as well as on the global scores also. These findings can be elaborated by looking at the statistically significant individual items responses where TCE students perceived the environment more positively (Item No. 5, 27, 30, 33, 36, 42, 45, 46, 49). However, ICE had better scores than TCE on all the reverse coded items (Item No. 9, 17, 39, 50).These findings are difficult to explain but indicate a chance to reflect back on how far the ICE are truly integrated. Within the academic self-perception domain, the traditional students showed higher scores than integrated students; specifically in memorising and relevancy of teaching to career. This is in contrast with the earlier reported results, where integrated students showed higher scores. ${ }^{16}$ This may show that students in the integrated environment are overburdened and lack time to cope with the amount of information. The item 'previous strategies which worked before are working now' seems to be misinterpreted by the students because ICE students significantly scored lower than the TCE, which was not expected.

In contrast to students' scores, the faculty global DREEM scores was higher in ICE compared to TCE. 
These results show that despite the complex operations and burden of ICE, the faculty has started adapting to the ICE. The difference in the academic self-perception and teaching perception domains is reflected in the global score, although all other domains scores were similar between TCE and ICE. The findings are consistent with the international reported data.4,16,19

Within the academic self-perception domain, the ICE faculty scores on individual items Nos. 31, 41 and 27 were higher than the TCE faculty. These results are plausible since one of the strengths of the ICE is seeding the logical and problem-solving skills in the students. 20 This also shows that the good mix of scenario-based learning and early exposure of clinical teaching to the pre-clinical students made them more empathetic compared to TCE. ${ }^{21}$ The TCE (0.68) more than ICE (1.4) admitted that they ridicule the students. Behavioural issues from the faculty have also been reported elsewhere, ${ }^{22}$ but these results are the first showing this negative trend in the ICE locally. These results are alarming showing the negative behaviour prevalent in the faculty. No curriculum can be made successful without the element of respect among the stakeholders. ${ }^{23}$

Similar to earlier stated findings, 24 the individual statement analysis identified that the teachers knowledge and competencies rated well, not only by the faculty themselves but by the students also.

In contrast to earlier reports, 15 the perceptions of traditional faculty were found closer to their students compared to the perception of integrated faculty with their students. In all the domains, the integrated faculty perceptions were overestimated compared to their students. These results again showed a gap in the perceptions of faculty and students in integrated environment. This could be due to the fast pace of the integrated curricular environment when the teacher may not find time to stop and look back where their students stand. These results highlight the significance of periodic teachers training, involving students while setting and reviewing the curricular objectives.

\section{CONCLUSION}

Overall, the integrated curriculum environment faculty and students both had more positive than negative perceptions of environment. However, the traditional curricular environment students scored higher than the above. This study uncovers a difference in the perceptions of students and faculty working in the integrated curricular environment. All the educational environment areas, represented by negative items, need to be addressed and worked upon. The results showed that the difference between the faculty and students DREEM score is more pronounced in integrated educational environment than in the traditional educational environment.

\section{REFERENCES}

1. Genn JM. AMEE Medical Education Guide No. 23 (Part 1): Curriculum, environment, climate, quality and change in medical education-a unifying perspective. Med Teach 2001; 23:337-44.

2. WFME. WFME Executive Council on international standards in medical education. 1998.

3. Farajpour A, Raisolsadat SMA, Mostafavian Z. Perception of educational environment among undergraduate students of health disciplines in an Iranian university. Int J Med Educ 2017; 8:300-6.

4. Shehnaz SI, Sreedharan J, Gomathi KG. Does curricular change improve faculty perceptions of student experiences with the educational environment? A preliminary study in an institution undergoing curricular change. J Educ Eval Health Prof 2014; $11: 7$.

5. Mirghani HEM. The academic environment and approach to learning effects on academic performance among Sudanese medical students. Med Ed Publish 2017; 6:37.

6. Abraham RR, Pallath V, Am C, Ramnarayan K, Kamath A. Avenues for professional development: faculty perspectives from an Indian medical school. Kathmandu Univ Med J (KUMJ) 2012; 10:60-5.

7. Altemani $\mathrm{AH}$, Merghani $\mathrm{TH}$. The quality of the educational environment in a medical college in Saudi Arabia. Int $\mathrm{J}$ Med Educ 2017; 8:128-32.

8. Soliman MM, Sattar K, Alnassar S, Alsaif F, Alswat K, Alghonaim $\mathrm{M}$, et al. Medical students' perception of the learning environment at King Saud University Medical College, Saudi Arabia, using DREEM Inventory. Adv Med Educ Pract 2017; 8:221-7.

9. Sarwar S, Tarique S. Perception of educational environment: Does it impact academic performance of medical students? J Pak Med Assoc 2016; 66:1210-4.

10. Chandler N, Henderson G, Park B, Byerley J, Brown WD, Steiner MJ. Use of a 360-degree evaluation in the outpatient setting: the usefulness of nurse, faculty, patient/family, and resident self-evaluation. J Grad Med Educ 2010; 2:430-4.

11. Salam A, Mohamad N, Siraj HH, Kamarudin MA, Yaman MN, Bujang SM. Team-based learning in a medical centre in Malaysia: Perspectives of the faculty. Natl Med J India 2014; 27:350.

12. Roff $S$. The dundee ready educational environment measure (DREEM) - a generic instrument for measuring students' perceptions of undergraduate health professions curricula. Med Teach 2005; 27:322-5.

13. Miles S, Leinster SJ. Comparing staff and student perceptions of the student experience at a new medical school. Med Teach 2009; 31:539-46.

14. Jawaid M, Raheel S, Ahmed F, Aijaz H. Students' perception of educational environment at public sector medical university of Pakistan. J Res Med Sci 2013; 18:417-21.

15. Shehnaz SI, Sreedharan J, Gomathi KG. Faculty and students' perceptions of student experiences in a medical school undergoing curricular transition in the United Arab Emirates. Sultan Qaboos Univ Med J 2012; 12:77-85.

16. Shehnaz SI, Sreedharan J. Students' perceptions of educational environment in a medical school experiencing curricular transition in United Arab Emirates. Med Teach 2011; 33:e37-42. 
17. Mayya S, Roff S. Students' perceptions of educational environment: a comparison of academic achievers and underachievers at Kasturba medical college, India. Educ Health (Abingdon) 2004; 17:280-91.

18. Al-Hazimi A, Al-Hyiani A, Roff S. Perceptions of the educational environment of the medical school in King Abdul Aziz University, Saudi Arabia. Med Teach 2004; 26:570-3.

19. Bouhaimed M, Thalib L, Doi SAR. Perception of the educational environment by medical students undergoing a curricular transition in Kuwait. Med Princip Pract 2009; 18: 204-8.

20. Irby DM, Cooke M, O'Brien BC. Calls for reform of medical education by the Carnegie Foundation for the Advancement of Teaching: 1910 and 2010. Acad Med 2010; 85:220-7.
21. Dandekar A, Relan A, Baillie S. Teaching pre-clerkship clinical skills via clinical exposure. Med Educ 2007; 41:1096-7.

22. Arzuman H, Yusoff MS, Chit SP. Big sib students' perceptions of the educational environment at the School of Medical Sciences, Universiti Sains Malaysia, using Dundee Ready Educational Environment Measure (DREEM) Inventory. Malays J Med Sci 2010; 17:40-7.

23. Bear AJ, Simpson D, Brown D, Bragg D, Marcdante K. Faculty and students perceive common tenets associated with medical student curriculum reform. Int J Med Educ 2013; 4:186-92.

24. Edgren G, Haffling AC, Jakobsson U, McAleer S, Danielsen N. Comparing the educational environment (as measured by DREEM) at two different stages of curriculum reform. Med Teach 2010; 32:e233-8. 